\title{
Characterization of the Immune Response during Infection Caused by Clostridioides difficile
}

\author{
Zohar Hamo 1,2, Maya Azrad ${ }^{2}$, Orna Nitzan 1,3 and Avi Peretz 1,2,* \\ 1 The Azrieli Faculty of Medicine, Bar Ilan University, Safed 13100, Israel; ZHamo@poria.health.gov.il (Z.H.); \\ ONitzan@poria.health.gov.il (O.N.) \\ 2 The Clinical Microbiology Laboratory, Baruch Padeh Medical Center, Poriya 15208, Israel; \\ MAzrad@poria.health.gov.il \\ 3 Unit of Infectious Diseases, Baruch Padeh Medical Center, Poriya 15208, Israel \\ * Correspondence: aperetz@poria.health.gov.il; Tel.: +972-4-665-2322
}

Received: 5 September 2019; Accepted: 7 October 2019; Published: 10 October 2019

\begin{abstract}
The high risk of complications and death following Clostridioides difficile infection (CDI) requires identifying patients with severe disease and treating them accordingly. We characterized the immune response of CDI patients in relation to infection severity. Concentrations of 28 cytokines and chemokines were measured in serum samples, obtained from 54 CDI patients within a median timeframe of $24-48 \mathrm{~h}$ after laboratory confirmation of $C$. difficile infection. Demographic and clinical data were retrospectively collected from medical records. Disease severity score was determined by "Score indices for Clostridioides difficile infection severity". Of 54 patients (mean age, 76.6 years, $61.1 \%$ female), $38(70.4 \%)$ had mild disease and $16(29.6 \%)$ had moderate disease. Seven cytokines were associated with a more severe CDI: granulocyte-macrophage colony-stimulating factor $(p=0.0106)$, interleukin (IL)-1 $\beta(p=0.004)$, IL-8 ( $p=0.0098)$, IL-12p70 $(p=0.0118)$, interferon- $\alpha(p=0.0282)$, IL-15 ( $p=0.0015)$, and IL-2 $(p=0.0031)$. Additionally, there was an increased T-helper 1 response in more severe cases of CDI. Cytokines may serve as biomarkers for early prediction of CDI severity. Better and earlier assessment of illness severity will contribute to the adjustment of medical treatment, including monitoring and follow-up.
\end{abstract}

Keywords: immune response; Clostridioides difficile; disease severity; biomarker; cytokines

\section{Introduction}

Clostridioides difficile infection (CDI) is one of the leading causes of nosocomial diarrhea. The infection often occurs following antibiotic treatment that alters the gut microbiota, enabling $C$. difficile to thrive and cause symptoms ranging from mild diarrhea to severe colitis and death [1].

Several factors contribute to CDI pathogenesis including the bacteria's abilities to produce toxins and to form spores. The observation that $C$. difficile may colonize healthy people without causing disease has advocated the idea that the host immune response also contributes to CDI progress, among other host-dependent factors [2].

The gastrointestinal system is the first line of defense against bacteria, viruses, fungi, and parasites. During bacterial infections, the innate immune system is activated, primarily in the intestinal mucus. The toxins released by $C$. difficile in the intestine cause dissociation of tight junctions and loss of epithelial integrity. In order to impede the damage and to prevent toxins from spreading into the bloodstream, T-helper cells (Th cells) release cytokines and activate a cascade of pro-inflammatory cytokines and other mediators that propagate the inflammatory process [2]. Naive Th cells differentiate into Th1, Th2, or Th17 effector cells that are antagonistic to each other and secrete different cytokines. Additionally, each pathogen elicits a typical Th response. It was found that two principal cytokines, interleukin (IL)-6 
and tumor necrosis factor alpha (TNF $\alpha)$, significantly exacerbate inflammation caused by $C$. difficile in accordance with infection severity [3].

The emergence of a particularly virulent $C$. difficile strain called Ribotype 027 (NAP1) over the last decade has caused a significant increase in CDI frequency, illness severity and mortality. NAP1 is characterized by a relatively high resistance to fluoroquinolone antibiotics, higher sporulation rate and increased secretion of toxins than other strains, as well as secretion of binary toxin [4]. This toxin disaggregates the actin cytoskeleton and induces effusion in intestinal epithelial cell cultures, eventually leading to apoptosis [5]. Several NAP1 outbreaks were identified in hospitals and in long-term care facilities in Israel [4].

At present, there is no reliable marker for the assessment of CDI severity and prognosis. Recently, cytoskeletal Tropomyosin (Tpm) was suggested as a new marker for CDI [6]. Although the sensitivity of Tpm detection in feces was high $(93.2 \%)$, its specificity was quite low $(53.7 \%)$. Another publication has proposed the detection of volatile organic compounds (VOC) in patients' feces [7]. However, this requires thermal desorption-gas chromatography-mass spectrometry or the development of other instrumentation. In light of CDI's high risk of complications, early and more accurate evaluation of its severity would be extremely valuable for rapid and specific treatment administration. Therefore, it is important to find a specific biomarker that could indicate disease severity. Consequently, it may be possible to adjust the treatment and follow-up required for each CDI patient by measuring these markers. In this study, we characterized the immune response of CDI patients in relation to infection severity. We hypothesized that a more severe disease is associated with the release of higher levels of cytokines and chemokines and hence, with a stronger immune response.

\section{Materials and Methods}

\subsection{Study Population}

The study population included patients diagnosed with CDI that were hospitalized at the Baruch Padeh Medical Center, between November 2015 and May 2017. Patients with sepsis due to causes other than CDI, and bacteremia were excluded from the analysis. The study was approved by the Poriya Baruch Padeh Medical Center Ethics Committee (Approval number, POR-0085-15, 08/02/2016). All of the participants signed an informed consent prior to enrolling in the study.

All CDI cases were confirmed for toxigenic $C$. difficile by stool examination using the GeneXpert C. difficile polymerase chain reaction (PCR) assay (Cepheid, Sunnyvale, CA, USA), identifying three targets: Toxin B, Binary Toxin, and presence of tcdC deletion. Laboratory parameters such as: C-reactive protein, white blood cell levels, as well as the percentage of neutrophils and lymphocytes were taken from each patient's medical record from the day the CDI was diagnosed.

\subsection{Measurement of Cytokine Concentrations}

Blood samples were collected within 24-48 h of the positive diagnostic result, and the serum was separated by centrifugation. Serum cytokine levels were determined using multiplex sandwich immunoassays with the Milliplex Human 41 Cytokine/Chemokine Premixed Kit (Millipore; Billerica, MA, USA) according to the manufacturer's protocol. The kit includes 28 cytokines and chemokines: IL-1 $\alpha$, IL-1 $\beta$ IL-1Ra, IL-2, IL-4, IL-5, IL-6, IL-7, IL-10, IL-12p40, IL-12p70, IL-13, IL-15, IL-17A, granulocyte-colony stimulating factor (G-CSF), granulocyte-macrophage colony-stimulating factor (GM-CSF), endothelial growth factor (EGF), eotaxin, fibroblast growth factor 2 (FGF2), IL-8, interferon gamma-induced protein 10 (IP-10), monocyte chemoattractant protein 1 (MCP-1), macrophage inflammatory protein $\alpha$ (MIP1 $\alpha)$, macrophage inflammatory protein $\beta$ (MIP1 $\beta)$, vascular endothelial growth factor (VEGF), tumor necrosis factor $\alpha$ (TNF $\alpha$ ), interferon $\alpha 2$ (IFN $\alpha 2)$ and interferon $\gamma(\operatorname{IFN} \gamma)$.

Serum of patients with positive toxigenic $C$. difficile results were combined with pre-mixed antibody-coupled magnetic fluorescent beads and assay buffer and incubated at $4{ }^{\circ} \mathrm{C}$ on a micro-titer plate shaker overnight. The following day, the samples were washed, pulled down using a magnetic 
plate washer and then incubated with biotin-conjugated secondary detection antibodies for one hour at room temperature. The samples were then washed again. A streptavidin-phycoerythrin detection solution was added to the samples and this mixture was incubated for $30 \mathrm{~min}$ at room temperature. Following incubation, sheath fluid was added to each sample well and the plate was read on the Luminex $200^{\mathrm{TM}}$ florescence reader (Luminex Molecular Diagnostic; Toronto, ON, Canada). Results of samples that were below the kit's identification threshold were excluded from the final analysis.

\subsection{Analysis of T-Cell Responses}

To understand the role of T-helper (Th) cells in CDI pathogenesis, Th1 and Th2 response was analyzed by calculating the ratio of IL-12p70 to IL-10, and the ratio of IL-12p70 to IL-5. The Th1 and Th17 response was analyzed by calculating the ratio of IL-12p70 to IL-17A, as previously described [8].

\subsection{Disease Severity Scoring and Demographic Data Collection}

CDI severity was evaluated by the severity score index (SSI) developed by Velazquez-Gomez et al. [9]. One point was given for each of the following parameters: changes in consciousness, pain/abdominal bulges, leukocytes above 20,000 cells $/ \mu \mathrm{L}$ or below 1500 cells $/ \mu \mathrm{L}$, albumin below $2.5 \mathrm{mg} / \mathrm{dL}$, ascites/colitis, tachycardia above $110 \mathrm{ppm}$, mean arterial pressure below $65 \mathrm{mmHg}$ and transfer to the intensive care unit.

An SSI of 0-3 points was defined as mild CDI and an SSI of 4-7 points was defined as moderate CDI.

The following demographic and clinical data were retrospectively collected from the patients' medical records: age, gender, community versus nosocomial-acquired CDI, death during hospitalization, white blood cell count, albumin level, creatinine level, and C-reactive protein level.

\subsection{Toxin Detection}

Toxins A and B were detected using the CerTest Clostridium difficile GDH+ Toxin A + B kit according to the manufacturer's instructions (Certest Biotec, S.L, San Mateo de Gállego, Zaragoza, Spain). The kit is a colored chromatographic assay for qualitative detection of $C$. difficile antigen glutamate dehydrogenase and Toxins A and B in stool samples. The sample was mixed with a test solution that contains mouse monoclonal antibodies anti-GDH/Toxin A/Toxin B conjugated to red polystyrene latex. When GDH antigen/Toxin A/Toxin B is present in the sample, the antigen/toxin reacts with its specific antibodies in the test solution and this complex is captured by the antibodies in the test strips, resulting in a visible red line.

\subsection{Statistical Analysis}

The data were analyzed using SAS ${ }^{\circledR}$ version 9.3 (SAS Institute, Cary, NC, USA). Categorical variables were summarized by number and percentage and continuous data were summarized by mean, standard deviation (SD), median, minimum and maximum. The Non-parametric Wilcoxon-Mann-Whitney Rank sum test for independent samples was applied for analyzing the differences in distribution of cytokine levels between mild and moderate CDI severity groups.

All tests applied were two-tailed, and a $p$ value of $5 \%$ or less was considered statistically significant.

\section{Results}

\subsection{Patient Epidemiologic Data}

Fifty-four patients aged 46-98 years (mean age, 76.6 years, $61.1 \%$ female) positive for C. difficile were included in the study. Table 1 summarizes the demographic and clinical characteristics of the patients. Most CDI cases (37/54, 68.5\%) were nosocomial, and the rest were community acquired. CDI severity was mild in 38 patients $(70.4 \%)$ and moderate in 16 patients $(29.6 \%)$. The most common isolated bacterial strains had both A + B toxin (34/54 patients, 63\%). Six isolates (11.1\%) had Toxin A and $14(25.9 \%)$ had Toxin B. 
Table 1. Clinical and demographic characteristics of patients with Clostridioides difficile infection (CDI).

\begin{tabular}{cc}
\hline Parameter & N (\%) \\
\hline Gender & $21(38.9)$ \\
Male & $33(61.10)$ \\
Female & \\
\hline Disease severity & $38(70.4)$ \\
Mild & $16(29.60)$ \\
Moderate & \\
\hline In- hospital mortality & $39(72.2)$ \\
Alive & $15(27.8)$ \\
Dead & \\
Toxin production & $6(11.1)$ \\
Toxin A & $14(25.9)$ \\
Toxin B & $34(63)$ \\
Toxins A + B & $37(68.5)$ \\
\hline Infection acquisition & $17(31.5)$ \\
Nosocomial &
\end{tabular}

In general, patients with CDI were characterized by higher values of white blood cells, albumin, creatinine, and C-reactive protein (compared with the normal range of these parameters) (Table 2).

Table 2. Patients' biochemical parameters.

\begin{tabular}{cccc}
\hline Biochemical Parameter & Mean \pm SD & Median (min, max) & Normal Range \\
\hline Albumin $(\mathrm{g} / \mathrm{dL})$ & $2.6 \pm 0.6$ & $2.4(1.1,4.3)$ & $3.4-5.4$ \\
Creatinine $(\mathrm{mg} / \mathrm{dL})$ & $1.9 \pm 1.5$ & $1.2(0.3,7.8)$ & $0.6-1.2$ \\
C-reactive protein $(\mathrm{mg} / \mathrm{L}) *$ & $71 \pm 32.2$ & $82.1(6.4,100)$ & $0-5$ \\
Lymphocytes (\%) & $13.5 \pm 11.2$ & $9.4(1.1,60.7)$ & $22-43$ \\
Neutrophils $(\%)$ & $78.2 \pm 13.3$ & $83.1(23.9,96.2)$ & $40-70$ \\
White blood cells (cells/ $\mu \mathrm{L})$ & $15,803.3 \pm 10,053.7$ & $15,285(1700,70,000)$ & $4300-10,800$ \\
\hline
\end{tabular}

* C-reactive protein above $100 \mathrm{mg} / \mathrm{L}$ was considered 100 .

\subsection{Characterization of the Immune Response in CDI Patients}

In order to find a biological marker that could correlate with disease severity, the level of 28 inflammatory mediators was measured in the patients' serum and compared between patients with mild and moderate CDI (Table 3). Of these 28 inflammatory mediators, significantly higher levels of seven cytokines were found in the moderate CDI group when compared with the mild CDI group: GM-CSF $(p=0.0106)$, IL-1 $\beta(p=0.004)$, IL-8 $(p=0.0098)$, IL-12p70 $(p=0.0118)$, INF- $\alpha(p=0.0282)$, IL-15 ( $p=0.0015)$, and IL-2 ( $p=0.0031)$ (Table 3, Figure 1). In addition, there was a trend for higher release of IFN- $\gamma$ in patients with moderate CDI $(p=0.07)$.

Table 3. Serum inflammatory mediators' levels (cytokines, chemokines and growth factors) in patients with CDI divided into mild and moderate CDI groups.

\begin{tabular}{cccc}
\hline Cytokine $(\mathrm{pg} / \mathrm{mL})$ & $\begin{array}{c}\text { Mild } \\
(\boldsymbol{n}=\mathbf{3 8}) \\
\text { Mean (Range) }\end{array}$ & $\begin{array}{c}\text { Moderate } \\
(\boldsymbol{n}=\mathbf{1 6}) \\
\text { Mean (Range) }\end{array}$ & $p$-Value \\
\hline EGF & $95.7(0-325.7)$ & $122.2(5.3-438.9)$ & 0.8875 \\
Eotaxin & $156(28.1-359.8)$ & $140.5(25.3-280)$ & 0.7702 \\
FGF2 & $66.6(0-255.9)$ & $215.8(0-826.5)$ & 0.0561 \\
G-CSF & $142.1(0-1881.8)$ & $172.4(41.2-1009.2)$ & 0.1463 \\
GM-CSF & $7.7(0-140.3)$ & $93.4(0-877.4)$ & $0.0106^{*}$ \\
\hline
\end{tabular}


Table 3. Cont.

\begin{tabular}{cccc}
\hline Cytokine (pg/mL) & $\begin{array}{c}\text { Mild } \\
(\boldsymbol{n = 3 8 )} \\
\text { Mean (Range) }\end{array}$ & $\begin{array}{c}\text { Moderate } \\
(\boldsymbol{n}=\mathbf{1 6}) \\
\text { Mean (Range) }\end{array}$ & $p$-Value \\
\hline IFN- $\gamma$ & $23.7(0-149.4)$ & $53.4(0-319)$ & 0.07 \\
IL-10 & $25.4(0-96.6)$ & $122.5(0-1116.4)$ & 0.0924 \\
IL-12p40 & $11.4(0-149.9)$ & $33.3(0-344.2)$ & 0.5672 \\
IL-12p70 & $20.5(0-466.2)$ & $64.7(0-447.8)$ & 0.0118 \\
IL-13 & $20.4(0-507)$ & $8.7(0-100.8)$ & 0.8731 \\
IL-15 & $5.7(0-16.6)$ & $30.1(0.7-131.9)$ & 0.0015 \\
IL-17A & $23.4(0-203.1)$ & $30.2(0-194.4)$ & 0.3134 \\
IL-1R $\alpha$ & $150(0-925.5)$ & $414.5(0-2836.3)$ & 0.132 \\
IL-1 $\alpha$ & $45.6(0-765)$ & $115.4(0-1330.1)$ & 0.5601 \\
IL-1 $\beta$ & $3.2(0-29.5)$ & $20.3(0-113.5)$ & 0.004 \\
IL-2 & $2.4(0-36.2)$ & $14.9(0-104.7)$ & 0.0031 \\
IL-4 & $7.2(0-209.4)$ & $10.4(0-83.4)$ & 0.1327 \\
IL-5 & $4.1(0-33.9)$ & $3.2(0-26.6)$ & 0.8765 \\
IL-6 & $74(0-657)$ & $80(0-296.5)$ & 0.452 \\
IL-7 & $9.2(0-28.5)$ & $14.4(0-108.5)$ & 0.8201 \\
IL-8 & $88(14.2-354.5)$ & $309.8(28.5-2033.5)$ & 0.0098 \\
INF- $\alpha$ & $22.3(0-297.4)$ & $69.3(0-399)$ & 0.0282 \\
IP-10 & $527.5(0-2969.9)$ & $640.1(84-3806)$ & 0.6873 \\
MCP-1 & $945.3(81.8-2817.7)$ & $1090.9(143.5-3659.2)$ & 0.7682 \\
MIP 1 $\alpha$ & $17.5(0-56.1)$ & $27(0-85)$ & 0.3619 \\
MIP 1 $\beta$ & $44.4(5-190.3)$ & $80.5(13.9-295.6)$ & 0.1404 \\
TNF $\alpha$ & $35.5(15.2-89.6)$ & $38.7(9.7-89.7)$ & 0.6854 \\
VEGF & $413.6(41.9-1679.5)$ & $1123.6(0-9426)$ & 0.7416 \\
\hline
\end{tabular}

EGF, endothelial growth factor; FGF, fibroblast growth factor 2; G-CSF, granulocyte colony-stimulating factor; GM-CSF, granulocyte-macrophage colony-stimulating factor; IFN, interferon; IL, interleukin; IP-10, interferon gamma-induced protein; MCP-1, monocyte chemoattractant protein 1; MIP, macrophage inflammatory protein; VEGF, vascular endothelial growth factor. * Bold values symbolize statistical significance.

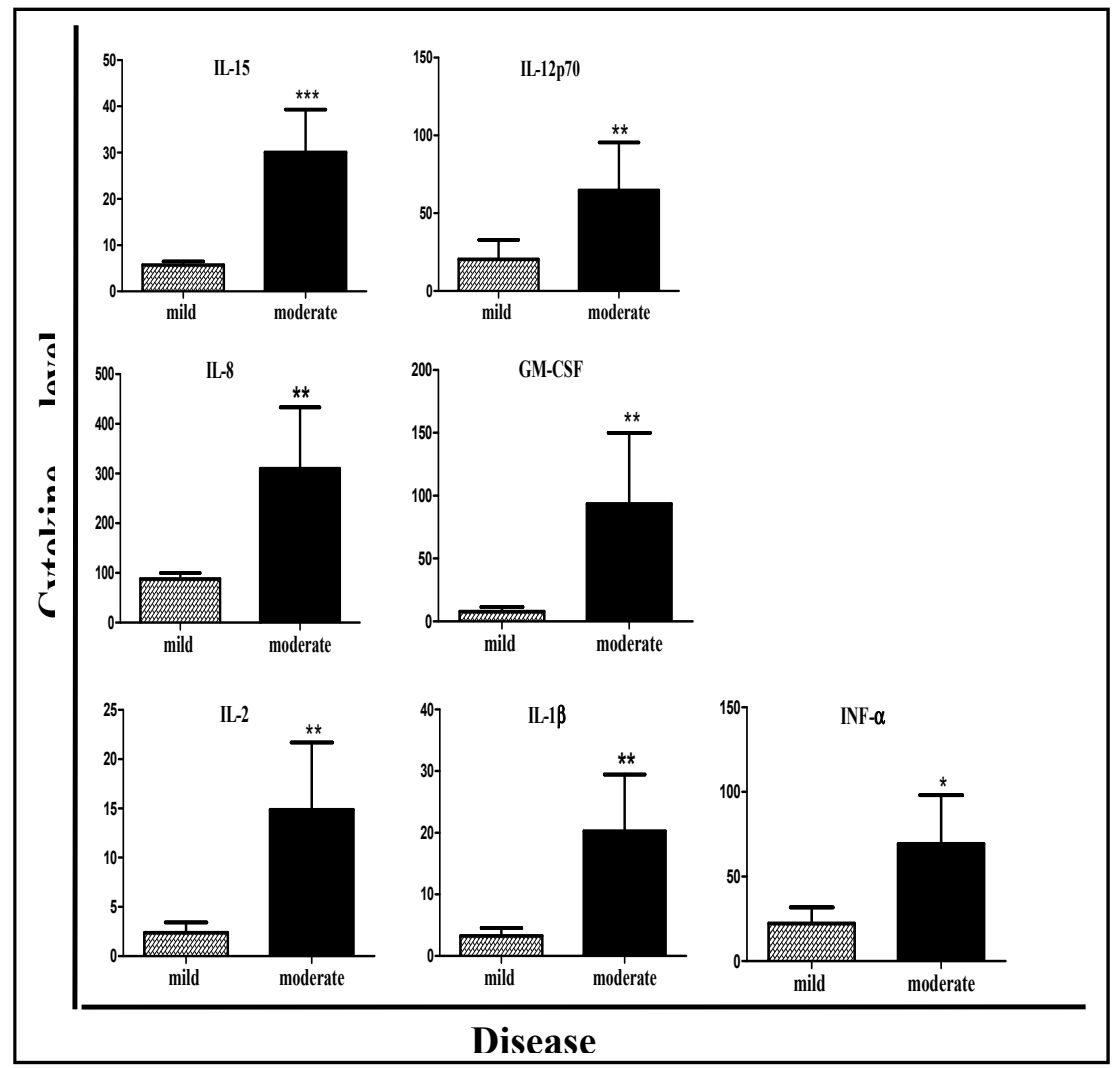

Figure 1. Serum inflammatory mediator levels correlate with disease severity of CDI patients. 
Moderate CDI patients had higher inflammatory mediator levels than patients with mild disease. ${ }^{*} p<0.05,{ }^{* *} p<0.01,{ }^{* * *} p<0.001$.

Assessment of the Th response showed that the IL-12p70/IL-5 ratio was 6.58-fold higher in the group of patients with moderate disease (mean 12.78) than in the group with mild disease (mean 1.94, $p=0.0001$ ), suggesting an increased Th1 response in patients with a more severe disease (Figure 2).

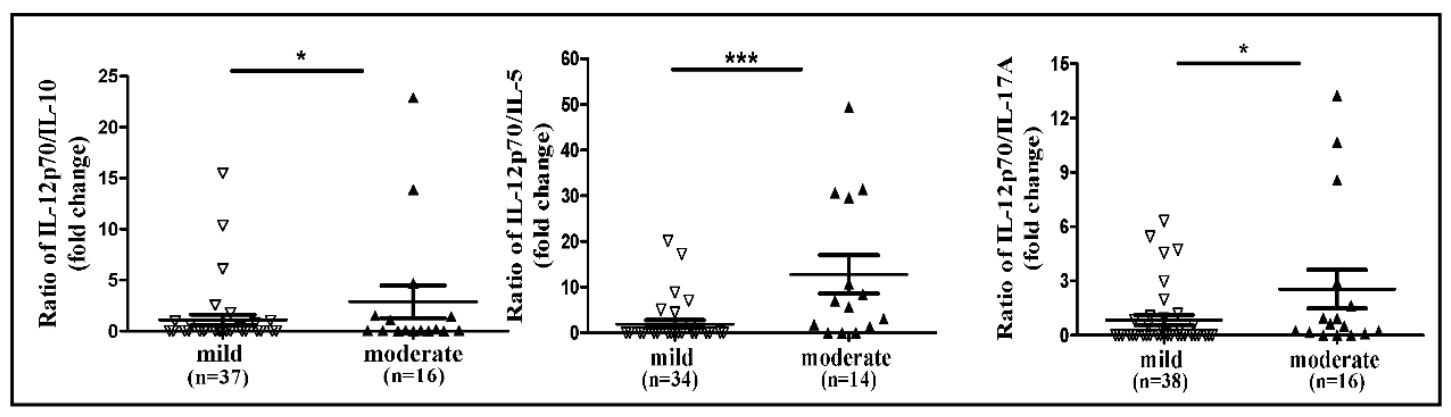

Figure 2. Ratio of Th1 to Th2 cells and Th1 to Th17 associated with severe CDI. ${ }^{*} p<0.05,{ }^{* *} p<0.01$, $* * * p<0.001$.

The IL-12p70/IL-10 ratio was 2.61-fold higher in the group with moderate disease (mean 2.86) than in the group with mild disease (mean 1.095, $p=0.02$ ). The IL-12p70/IL-17A ratio was 3.03-fold higher in the group with moderate disease (mean 2.55) than in the group with mild disease (mean 0.84 , $p=0.023$ ), suggesting a decrease in Th17 response in patients with more severe disease (Figure 2).

\section{Discussion}

In line with our hypothesis, we found an association between CDI severity and a stronger immune response. The levels of seven different cytokines were significantly higher in patients with moderate CDI: IL-15, IL-8, IL-2, IL-1 $\beta$, INF- $\alpha$, IL-12p70, and GM-CSF. These cytokines take part in the inflammatory response and are involved in its amplification, indicating their essential role in CDI pathogenesis.

IL-8 activates the chemotaxis mechanism for neutrophil recruitment and activation of innate lymphoid cells [10]. Previous studies have shown a positive correlation between CDI severity and high IL-8 levels in fecal samples of CDI patients [11,12]. High levels of fecal IL-8 also increase the risk of CDI recurrence [13]. Additionally, a specific polymorphism of IL-8 was associated with increased susceptibility to severe CDI [14]. Similar to IL-8, IL-1 $\beta$ is essential for host response and provides protection following infection and injury [15]. In addition to direct neutrophil recruitment, IL-1 $\beta$ also promotes IL-8 production, thus further increasing the levels of recruited neutrophils into the inflamed site [2]. Fecal concentration ratios of IL-1 $\beta /$ IL-Ra were significantly increased in patients with severe CDI compared to patients with mild CDI [11], supporting our findings.

GM-CSF promotes mucosal infections, including ones in the gastrointestinal tract $[16,17]$. It is involved in recruitment of neutrophils to the infection site [2], as was demonstrated in C. difficile-infected mice [18]. To the best of our knowledge, ours is the first report that shows that serum GM-CSF levels are associated with CDI severity.

Neutrophil infiltration is a well-known feature of CDI and is believed to amplify the host immune response [19]. As IL-8, IL-1 $\beta$ and GM-CSF are all involved in the attraction of neutrophils to the inflammation center, it is reasonable that higher levels of IL-8, IL-1 $\beta$ and GM-CSF correlate with a more severe condition.

IL-2 and IL-15 were also significantly increased in patients with moderate CDI, as was previously reported [8]. IL-2 is secreted by lymphocytes and plays a central role in stimulating the proliferation of mucous lymphocytes, natural killer (NK) cells, and macrophages [20]. The main role of IL-2 is the 
expansion of Th cell populations through increased expression of high-affinity IL-2 receptors [20]. In addition, IL-2, together with IL-15, increase the number of NK cells [21-24] and promote NK cells to produce cytokines such as TNF- $\alpha$, IFN- $\lambda$, and GM-CSF [25]. IL-15 indirectly affects neutrophil and monocyte chemotaxis to the infected site [26]. In macrophages, IL-15 promotes the production of pro-inflammatory cytokines such as TNF- $\alpha$, IL-1, and IL-6 [27].

An additional virulence factor of $C$. difficile that affects the immune response is S-layer proteins (SLPs), which are recognized by the host's Toll-like receptor 4 (TLR4). This interaction activates a cascade of events that eventually leads to the maturation of dendritic cells (DS), characterized by cytokine production [28]. It was shown that identification of pure C. difficile SLPs by TLR4 activates the Nf-kB signaling pathway, and consequently, leads to Th1 and Th17 responses [29]. Th1 cells induce the inflammatory responses that are part of the host cellular immunity, while Th17 is more involved in tissue destruction [30]. In our current study, IL-12p70 levels were significantly increased in patients with moderate CDI. As this cytokine is produced by Th1 and Th17 cells, this result suggests a considerable involvement of Th1 and Th17 in severe CDI. IFN- $\alpha$ also induces Th1 response, as was demonstrated by the significantly higher levels of IFN- $\alpha$ noted in patients with moderate CDI [31]. IFN- $\alpha$ increases the recruitment of cytotoxic T-cells, NK cells, and phagocytes. In addition, IFN- $\alpha$ promotes the differentiation of naive T-cells into Th1 phenotype [32,33]. This is the first time that IFN- $\alpha$ has been found to be associated with the severity of CDI.

We found an increase in release of IFN- $\gamma$ in patients with moderate CDI. IFN- $\gamma$ is a potent mediator of innate immunity at mucosal sites, including the gastrointestinal tract [34-36]. Neutrophils produce IFN- $\gamma$ in response to CDIs [36]. Abt et al. [37] has suggested a critical role for IFN- $\gamma$-producing type I innate lymphoid cells in mediating host survival during C. difficile colitis.

For further elucidation of Th1, Th2, and Th17 involvement in severe CDI, we calculated the ratio of IL-12p70/IL-10, and IL-12p70/IL-5 as a measure for Th1/Th2 response proportion, and the IL-12p70/IL-17A as a measure for Th1/Th17 response. We found a higher Th1/Th2 ratio in moderate disease compared with mild disease. These results match the change in the levels of specific Th1 cytokines, such as IL-2, in the mild and moderate CDI groups. Although a recent study of 36 CDI patients, has found opposite results, according to which there was a shift from Th1 to Th2 response when the disease was more severe [8], it is possible that blood sampling was performed at a different stage of the disease than our sampling. It is well-established that immune tolerance against commensal bacteria leads to the induction of protective $\mathrm{T}$ regulatory cells (iTreg) in the gut, while antibiotic treatment, which changes the microbiome, down-regulates iTreg and up-regulates Th1 and Th17 cells, resulting in a mild pro-inflammatory response. As $C$. difficile infection further damages the epithelium and increases cellular immune response, such a condition may result in a more intense inflammatory reaction [3]. Th2 cells, which regulate humoral immunity, may be involved in a later stage of CDI [38]. Regarding Th17 response, we found that the IL-12p70/IL-17A ratio was higher in moderate disease compared with mild disease, indicating that Th17 response did not increase when the disease was more severe. This finding does not correlate with previous reports in which Th17 response increased with disease severity $[8,39]$ and was correlated with higher odds for death post-infection [39]. One reason for this discrepancy may be that we investigated the disease at an early stage, in which Th17 response had not yet increased, or that patient co-morbidities caused variance in the types of cytokine secretion and T-cell response.

We expected to find increased levels of IL- 6 and TNF- $\alpha$ levels in more severe CDI, because both of these pro-inflammatory cytokines have been shown to increase during the activation of the innate immune system. Additionally, a previous publication has shown that IL-6 levels increased with disease severity [39]. However, no statistically significant differences were noted in the level of these cytokines between mild and moderate CDI. A possible explanation is that the patients' co-morbidities masked part of the immune response. The study has several limitations. First, it is limited by its small sample size. Second, CDI severity was measured by one of several scales available, and only mild and moderate CDI were correlated with cytokine levels. Third, although serum sampling was done within 
24-48 $\mathrm{h}$ of receiving a positive result for $C$. difficile presence, the samples may not have been collected at the same stage in terms of the immune response. Therefore, for further studies, we suggest collecting several blood samples on sequential days during hospitalization in order to detect the time point at which a change in cytokine levels occurs. Fourth, no comparison was made to intestinal disease not caused by C. difficile.

In summary, our results point to the involvement of several pro-inflammatory cytokines in CDI pathogenesis, which is reflected in recruitment and activation of neutrophils, NK cells, and T-cell differentiation. In line with our hypothesis, disease severity correlated with the intensification of this immune response. In addition, the significant association between disease severity and increased levels of IL-15, IL-8, IL-2, IL-1 $\beta$, INF- $\alpha$, IL-12p70, and GM-CSF indicates that these cytokines may serve as effective diagnostic tools to predict disease severity in the case of moderate CDI. These cytokines are easy to measure and the results are obtained quickly. Therefore, we suggest that in parallel to the initial identification of CDI, testing cytokine levels in the blood as part of routine blood tests may be effective for predicting disease severity, in addition to other clinical data. Recently, another inflammatory marker-Procalcitonin, a precursor peptide of calcitonin — has been found to be elevated during CDI and may be correlated with disease severity. Measurement of this biomarker is easy and quick [40]. Better and earlier assessment of CDI severity will contribute to adjustment of the medical treatment, allowing for improved patient care and may reduce patient mortality. Further prospective studies are needed to investigate the efficacy of pro-inflammatory cytokines in the diagnosis and follow-up phases of CDI, as an alternative or as a supplement to blood tests.

Author Contributions: Conceptualization, Z.H., M.A., O.N. and A.P.; methodology, Z.H. and M.A.; validation, Z.H., M.A. and A.P.; formal analysis, Z.H., M.A. and A.P.; data curation, Z.H. and O.N.; Writing-Original draft preparation, Z.H., M.A. and A.P.; Writing-Review and editing, Z.H., M.A., O.N. and A.P.; visualization, Z.H., M.A. and A.P.; supervision, M.A. and A.P.; project administration, M.A. and A.P.; funding acquisition, M.A. and A.P.

Funding: This research was funded by the Chief Scientist's Office of the Ministry of Health, Israel, grant number 3-000-14515.

Conflicts of Interest: The authors declare no conflict of interest.

\section{References}

1. Bartlett, J. Clostridium difficile: History of its role as an enteric pathogen and the current state of knowledge about the organism. Clin. Infect. Dis. 1994, 18 (Suppl. 4), S265-S272. [CrossRef]

2. Madan, R.; Petri, W.A., Jr. Immune responses to Clostridium difficile infection. Trends Mol. Med. 2012, 18, 658-666. [CrossRef]

3. Solomon, K. The host immune response to Clostridium difficile infection. Ther. Adv. Infect. Dis. 2013, 1, 19-35. [PubMed]

4. Adler, A.; Miller-Roll, T.; Bradenstein, R.; Block, C.; Mendelson, B.; Parizade, M.; Paitan, Y.; Schwartz, D.; Peled, N.; Carmeli, Y.; et al. A national survey of the molecular epidemiology of Clostridium difficile in Israel: The dissemination of the ribotype 027 strain with reduced susceptibility to vancomycin and metronidazole. Diagn. Microbiol. Infect. Dis. 2015, 83, 21-24. [CrossRef]

5. Kim, J.; Seo, M.; Kang, J.O.; Choi, T.Y.; Pai, H. Clinical and microbiologic characteristics of Clostridium difficile infection caused by binary toxin producing strain in Korea. Infect. Chemother. 2013, 45, 175-183. [CrossRef] [PubMed]

6. Usacheva, E.A.; Peterson, L.R.; Mendoza, K.; Schora, D.M.; Hossain, M.M.; Jin, J.P. Cytoskeletal Tropomyosin as a Biomarker in Clostridium difficile Infection. J. Clin. Med. Res. 2019, 11, 98-105. [CrossRef] [PubMed]

7. Patel, M.; Fowler, D.; Sizer, J.; Walton, C. Faecal volatile biomarkers of Clostridium difficile infection. PLoS ONE 2019, 14, e0215256. [CrossRef]

8. Yu, H.; Chen, K.; Sun, Y.; Carter, M.; Garey, K.W.; Savidge, T.C.; Devaraj, S.; Tessier, M.E.; von Rosenvinge, E.C.; Kelly, C.P.; et al. Cytokines are markers of the Clostridium difficile-induced inflammatory response and predict disease severity. Clin. Vaccine Immunol. 2017, 24. [CrossRef]

9. Velazquez-Gomez, I.; Rocha-Rodriguez, R.; Toro, D.; Gutierrez-Nuñez, J.J.; Gonzalez, G.; Saavedra, S. A severity score index for Clostridium difficile infection. Infect. Dis Clin. Pract. 2008, 16, 376-378. [CrossRef] 
10. Abt, M.C.; McKenney, P.T.; Pamer, E.G. Clostridium difficile colitis: Pathogenesis and host defence. Nat. Rev. Microbiol. 2016, 14, 609-620. [CrossRef]

11. Steiner, T.S.; Flores, C.A.; Pizarro, T.T.; Guerrant, R.L. Fecal lactoferrin, interleukin-1beta, and interleukin-8 are elevated in patients with severe Clostridium difficile colitis. Clin. Diagn. Lab. Immunol. 1997, 4, 719-722. [PubMed]

12. El Feghaly, R.E.; Stauber, J.L.; Deych, E.; Gonzalez, C.; Tarr, P.I.; Haslam, D.B. Markers of intestinal inflammation, not bacterial burden, correlate with clinical outcomes in Clostridium difficile infection. Clin. Infect. Dis. 2013, 56, 1713-1721. [CrossRef] [PubMed]

13. Garey, K.W.; Jiang, Z.D.; Ghantoji, S.; Tam, V.H.; Arora, V.; Dupont, H.L. A common polymorphism in the interleukin-8 gene promoter is associated with an increased risk for recurrent Clostridium difficile infection. Clin. Infect. Dis. 2010, 51, 1406-1410. [CrossRef]

14. Jiang, Z.D.; Garey, K.W.; Price, M.; Graham, G.; Okhuysen, P.; Dao-Tran, T.; LaRocco, M.; DuPont, H.L. Association of interleukin-8 polymorphism and immunoglobulin $\mathrm{G}$ anti-toxin A in patients with Clostridium difficile-associated diarrhea. Clin. Gastroenterol. Hepatol. 2007, 5, 964-968. [CrossRef] [PubMed]

15. Dinarello, C.A. Biologic basis for interleukin-1 in disease. Blood 1996, 87, 2095-2147. [CrossRef] [PubMed]

16. Lambrecht, B.N.; Hammad, H. Asthma: The importance of dysregulated barrier immunity. Eur. J. Immunol. 2013, 43, 3125-3137. [CrossRef]

17. Däbritz, J. Granulocyte macrophage colony-stimulating factor and the intestinal innate immune cell homeostasis in Crohn's disease. Am. J. Physiol. Gastrointest. Liver. Physiol. 2014, 306, G455-G465. [CrossRef]

18. McDermott, A.J.; Frank, C.R.; Falkowski, N.R.; McDonald, R.A.; Young, V.B.; Huffnagle, G.B. Role of GM-CSF in the inflammatory cytokine network that regulates neutrophil influx into the colonic mucosa during Clostridium difficile infection in mice. Gut Microbes. 2014, 5, 476-484. [CrossRef]

19. Hall, I.C.; O'Toole, E. Intestinal flora in new-born infants: With a description of a new pathogenic anaerobe, Bacillus difficilis. Am. J. Dis. Child. 1935, 49, 390-402. [CrossRef]

20. Gaffen, S.L.; Liu, K.D. Overview of interleukin-2 function, production and clinical applications. Cytokine 2004, 28, 109-123. [CrossRef]

21. Giri, J.G.; Ahdieh, M.; Eisenman, J.; Shanebeck, K.; Grabstein, K.; Kumaki, S.; Namen, A.; Park, L.S.; Cosman, D.; Anderson, D. Utilization of the beta and gamma chains of the IL-2 receptor by the novel cytokine IL-15. EMBO J. 1994, 13, 2822-2830. [CrossRef] [PubMed]

22. Giri, J.G.; Kumak, S.; Ahdieh, M.; Friend, D.J.; Loomis, A.; Shanebeck, K.; DuBose, R.; Cosman, D.; Park, L.S.; Anderson, D.M. Identification and cloning of a novel IL-15 binding protein that is structurally related to the alpha chain of the IL-2 receptor. EMBO J. 1995, 14, 3654-3663. [CrossRef] [PubMed]

23. Carson, W.E.; Fehniger, T.A.; Haldar, S.; Eckhert, K.; Lindemann, M.J.; Lai, C.F.; Croce, C.M.; Baumann, H.; Caligiuri, M.A. A potential role for interleukin-15 in the regulation of human natural killer cell survival. J. Clin. Invest. 1997, 99, 937-943. [CrossRef] [PubMed]

24. Morris, D.G.; Waters, S.M.; McCarthy, S.D.; Patton, J.; Earley, B.; Fitzpatrick, R.; Murphy, J.J.; Diskin, M.G.; Kenny, D.A.; Brass, A.; et al. Pleiotropic effects of negative energy balance in the postpartum dairy cow on splenic gene expression: Repercussions for innate and adaptive immunity. Physiol. Genom. 2009, 39, $28-37$. [CrossRef]

25. Miura, M.; Kato, H.; Matsushita, O. Identification of a novel virulence factor in clostridium difficile that modulates toxin sensitivity of cultured epithelial cells. Infect. Immun. 2011, 79, 3810-3820. [CrossRef]

26. Perera, P.Y.; Lichy, J.H.; Waldmann, T.A.; Perera, L.P. The role of interleukin-15 in inflammation and immune responses to infection: Implications for its therapeutic use. Microbes Infect. 2012, 14, 247-261. [CrossRef]

27. Alleva, D.G.; Kaser, S.B.; Monroy, M.A.; Fenton, M.J.; Beller, D.I. IL-15 functions as a potent autocrine regulator of macrophage proinflammatory cytokine production: Evidence for differential receptor subunit utilization associated with stimulation or inhibition. J. Immunol. 1997, 159, 2941-2951.

28. Ryan, A.; Lynch, M.; Smith, S.M.; Amu, S.; Nel, H.J.; McCoy, C.E.; Dowling, J.K.; Draper, E.; O’Reilly, V.; McCarthy, C.; et al. A role for TLR4 in Clostridium difficile infection and the recognition of surface layer proteins. PLoS Pathog. 2011, 7, e1002076. [CrossRef]

29. Twine, S.M.; Reid, C.W.; Aubry, A.; McMullin, D.R.; Fulton, K.M.; Austin, J.; Logan, S.M. Motility and flagellar glycosylation in Clostridium difficile. J. Bacteriol. 2009, 191, 7050-7062. [CrossRef] [PubMed] 
30. Qu, N.; Xu, M.; Mizoguchi, I.; Furusawa, J.; Kaneko, K.; Watanabe, K.; Mizuguchi, J.; Itoh, M.; Kawakami, Y.; Yoshimoto, T. Pivotal roles of T-helper 17-related cytokines, IL-17, IL-22, and IL-23, in inflammatory diseases. Clin. Dev. Immunol. 2013, 2013, 968549. [CrossRef]

31. Hermann, P.; Rubio, M.; Nakajima, T.; Delespesse, G.; Sarfati, M. IFN- $\alpha$ priming of human monocytes differentially regulates gram-positive and gram-negative bacteria-induced IL-10 release and selectively enhances IL-12p70, CD80, and MHC class I expression. J. Immunol. 1998, 161, 2011-2018. [PubMed]

32. Wu, C.Y.; Demeure, C.E.; Gately, M.; Podlaski, F.; Yssel, H.; Kiniwa, M.; Delespesse, G. In vitro maturation of human neonatal CD4 T lymphocytes. I. Induction of IL-4-producing cells after long-term culture in the presence of IL-4 plus either IL-2 or IL-12. J. Immunol. 1994, 152, 1141-1153. [PubMed]

33. Rijneveld, A.W.; Lauw, F.N.; Schultz, M.J.; Florquin, S.; Te Velde, A.A.; Speelman, P.; Van Deventer, S.J.; Van Der Poll, T. The role of interferon- $\gamma$ in murine pneumococcal pneumonia. J. Infect. Dis. 2002, 185, 91-97. [CrossRef] [PubMed]

34. Ishida, Y.; Maegawa, T.; Kondo, T.; Kimura, A.; Iwakura, Y.; Nakamura, S.; Mukaida, N. Essential involvement of IFN- $\gamma$ in Clostridium difficile toxin A-induced enteritis. J. Immunol. 2004, 172, 3018-3025. [CrossRef] [PubMed]

35. Ito, R.; Shin-Ya, M.; Kishida, T.; Urano, A.; Takada, R.; Sakagami, J.; Imanishi, J.; Kita, M.; Ueda, Y.; Iwakura, Y.; et al. Interferon $\gamma$ is causatively involved in experimental inflammatory bowel disease in mice. Clin. Exp. Immunol. 2006, 146, 330-338. [CrossRef] [PubMed]

36. El-Zaatari, M.; Chang, Y.M.; Zhang, M.; Franz, M.; Shreiner, A.; McDermott, A.J.; van der Sluijs, K.F.; Lutter, R.; Grasberger, H.; Kamada, N.; et al. Tryptophan catabolism restricts IFN- $\gamma$-expressing neutrophils and Clostridium difficile immunopathology. J. Immunol. 2014, 193, 807-816. [CrossRef] [PubMed]

37. Abt, M.C.; Lewis, B.B.; Caballero, S.; Xiong, H.; Carter, R.A.; Sušac, B.; Ling, L.; Leiner, I.; Pamer, E.G. Innate immune defenses mediated by two ILC subsets are critical for protection against acute Clostridium difficile infection. Cell Host Microbe 2015, 18, 27-37. [CrossRef]

38. Gerbino, E.; Carasi, P.; Mobili, P.; Serradell, M.A.; Gómez-Zavaglia, A. Role of S-layer proteins in bacteria. World J. Microbiol. Biotechnol. 2015, 31, 1877-1887. [CrossRef]

39. Saleh, M.M.; Frisbee, A.L.; Leslie, J.L.; Buonomo, E.L.; Cowardin, C.A.; Ma, J.Z.; Simpson, M.E.; Scully, K.W.; Abhyankar, M.M.; Petri, W.A., Jr. Colitis-Induced Th17 Cells Increase the Risk for Severe Subsequent Clostridium difficile Infection. Cell Host Microbe 2019, 25, 756-765. [CrossRef]

40. Shapiro, D.S.; Friedmann, R.; Husseini, A.; Ivgi, H.; Yinnon, A.M.; Assous, M.V. Can Procalcitonin Contribute to the Diagnosis of Clostridium difficile Colitis? Isr. Med. Assoc. J. IMAJ 2017, 19, 313-316. 